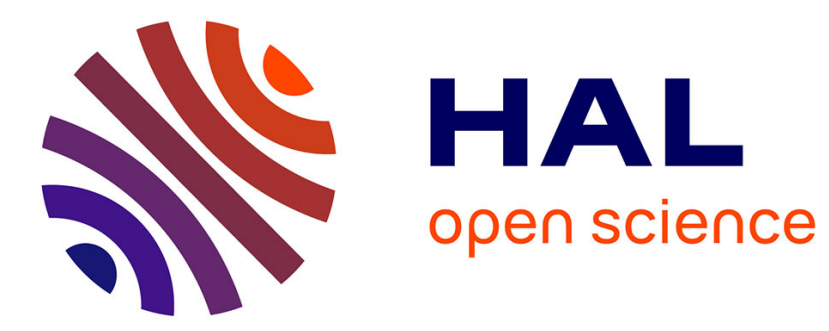

\title{
Barriers to electricity load shift in companies: A survey-based exploration of the end-user perspective
}

\author{
Mark Olsthoorn, Joachim Schleich, Marian Klobasa D
}

\section{To cite this version:}

Mark Olsthoorn, Joachim Schleich, Marian Klobasa D. Barriers to electricity load shift in companies: A survey-based exploration of the end-user perspective. Energy Policy, 2015, 76, pp.32 - 42. 10.1016/j.enpol.2014.11.015 . hal-01104611

\section{HAL Id: hal-01104611 \\ http://hal.grenoble-em.com/hal-01104611}

Submitted on 18 Jan 2015

HAL is a multi-disciplinary open access archive for the deposit and dissemination of scientific research documents, whether they are published or not. The documents may come from teaching and research institutions in France or abroad, or from public or private research centers.
L'archive ouverte pluridisciplinaire HAL, est destinée au dépôt et à la diffusion de documents scientifiques de niveau recherche, publiés ou non, émanant des établissements d'enseignement et de recherche français ou étrangers, des laboratoires publics ou privés. 


\title{
Barriers to electricity load shift in companies: a survey-based exploration of the end-user perspective
}

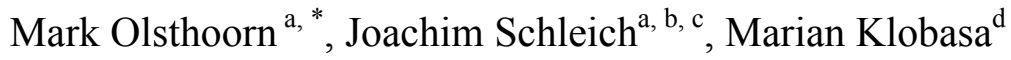

${ }^{\text {a }}$ Grenoble Ecole de Management, 12 rue Pierre Sémard, 38003 Grenoble, France, Phone : ++ 334568066 33, Fax : ++ 334767060 99, email: mark.olsthoorn@grenoble-em.com

${ }^{\mathrm{b}}$ Fraunhofer Institute for Systems and Innovation Research ISI, Breslauer Strasse 48, 76139 Karlsruhe, Germany, Phone: ++49 7216809 203, Fax: ++49 7216809 77203, e-mail: joachim.schleich@isi.fraunhofer.de

${ }^{\mathrm{c}}$ Virginia Polytechnic Institute and State University, Hutcheson Hall, Blacksburg, VA 24060 Blacksburg, Virginia, USA

${ }^{\mathrm{d}}$ Fraunhofer Institute for Systems and Innovation Research ISI, Breslauer Strasse 48, 76139 Karlsruhe, Germany, Phone: ++49 721 6809-287, Fax: ++49 7216809 77287, e-mail: marian.klobasa@isi.fraunhofer.de

* Corresponding author

When you cite this article, please cite the published version:

Olsthoorn, M.F., Schleich, J., Klobasa, M., 2015. Barriers to electricity load shift in companies: a survey-based exploration of the end-user perspective. Energy Policy 76, 32-42. 


\begin{abstract}
As countries move toward larger shares of renewable electricity, the slow diffusion of active electricity load management should concern energy policy makers and users alike. Active load management can increase capacity factors and thereby reduce the need for new capacity, improve reliability, and lower electricity prices. This paper conceptually and empirically explores barriers to load shift in industry from an end-user perspective. An online survey, based on a taxonomy of barriers developed in the realm of energy efficiency, was carried out among manufacturing sites in mostly Southern Germany. Findings suggest that the most important barriers are risk of disruption of operations, impact on product quality, and uncertainty about cost savings. Of little concern are access to capital, lack of employee skills, and data security. Statistical tests suggest that companies for which electricity has higher strategic value rate financial and regulatory risk higher than smaller ones. Companies with a continuous production process report lower barrier scores than companies using batch or justin-time production. A principal component analysis clusters the barriers and multivariate analysis with the factor scores confirms the prominence of technical risk as a barrier to load shift. The results provide guidance for policy making and future empirical studies.
\end{abstract}

Key words: load shift; load management; barriers 


\section{Highlights}

- We quantitatively assess barriers to load shift adoption among manufacturing firms

- Conceptually, we build on the literature on barriers to energy efficiency

- The most important barriers are interference with production and with product quality

- Companies with a continuous production process report lower barrier scores

- The barriers to load shift may be organized in distinct clusters via principal component analysis 


\section{Introduction}

Electricity generated from wind and solar is fast expanding and expected to take a prominent role in the future power supply, especially in OECD counties (e.g. IEA, 2012, 2014). Securing the reliability of electricity supply during the transition away from centralized, fossil fuelbased generation to such a system based on renewable energy sources is one of the major challenges for the energy system (Baritaud, 2012). In addition to flexible backup generation capacity, it requires an increase in storage technologies and 'virtual' systems such as smart grids and active load management (GEA, 2012). With active load management, residential and commercial electricity users contribute to balancing the electricity grid by dialing down or cycling electricity consuming appliances or machines in times of peak demand or supply shortages. It can prevent peak power generators (which exhibit high marginal costs) to be activated or avoid forced curtailments. Load shift has been applied for many years, mostly in the US, as a reliability supplement during emergency situations, but is now increasingly considered an effective substitute for supply (Kim and Shcherbakova, 2011). The benefits of load shift include higher capacity factors for existing capacity, less need for new capacity, improved reliability of the power grid, less congestion and transmission constraints, less price volatility, mitigation of market power, and lower electricity prices for end-users (Borenstein, 2005; Faruqui et al., 2007; Faruqui and Palmer, 2011; Joskow, 2012). As such, load shift is instrumental in achieving the high-level energy policy goals of a secure, affordable, and clean electricity system faster and at lower costs.

However, despite clear socio-economic benefits and sizeable potential (Grein and Pehnt, 2011; Hartkopf et al., 2012) load shift programs and practices have been slow to diffuse, in Europe as well as in the US (Greening, 2010; Torriti et al., 2010; Kim and Shcherbakova, 2011). Current industrial load shift practice is largely limited to bigger, energy-intensive production sites that apply load shift mainly for smoothing their own load profile (Grein and 
Pehnt, 2011). Significant unused load shift potentials can be expected in less energy-intensive sectors, where load shifting has hardly penetrated at all (Paulus and Borggrefe, 2011; VDE, 2012; Klobasa et al., 2014). Even where incentive structures are in place, barriers prevent energy users to adopt load shift to the extent expected (Kim and Shcherbakova, 2011; Torriti and Grünewald, 2014). Currently, we lack sufficient understanding why firms fail to adopt load shift. To the best of our knowledge, there is no academic literature that specifically addresses the barriers (and drivers) to load shift adoption by companies. A rich literature exists on barriers to adoption of energy efficiency measures (e.g., Sorrell et al., 2011; Fleiter et al., 2012a; Cagno et al., 2013). This literature may offer valuable insights but is not readily applicable in the context of load shift. Although both energy efficiency and load shift are costsaving, energy-related process innovations and have both technological and operational dimensions, load shift and energy efficiency differ on key aspects. Load shift can have a positive effect on energy efficiency of the system, but a company adopting load shift is unlikely to increase its own energy efficiency. The operational dimension is much larger for load shift, with lower upfront investments but recurring overhead and opportunity costs. Nonenergy benefits, such as lower noise levels or lower maintenance costs, can be significant and decisive for energy efficiency measures (Worrell et al., 2003; Cooremans, 2011; Fleiter et al., 2012b, Delmas and Pekovic, 2014) but do not hold for load shift. Besides, financial returns of load shift depend on multiple external factors, such as meteorological conditions and developments regarding available capacity in the market as load shift stands in competition with other ancillary service technologies such as electricity storage and also improved wind and solar forecasts, grid extensions and other effects impact the business case for load shift (Paulus and Borggrefe, 2011).

Taxonomies of barriers to energy efficiency may be transferrable to a large extent, but the relevance of individual barriers is not. A specific body of empirical work needs to be built in 
order to inform the design of efficient economic and behavioral instruments for the promotion of load shift. In that regard, this paper makes two contributions: (1) It is - to the best of our knowledge - the first academic work to empirically investigate the relevance of barriers to load shift adoption by industrial energy users from the energy user perspective, and (2) it adds to the conceptual understanding of load shift in industrial firms in its current stage of development by assessing the barriers structure and exploring the influence of company characteristics.

Three research questions structure this paper. We first ask: (Q1) Which barriers keep manufacturing businesses from adopting load shift? We focus on Southern Germany, where supply side intermittency is growing fast due to the strong diffusion of solar-PV alongside the phase-out of all nuclear power by 2022 (Klobasa et al., 2014). Conceptually, the empirical work relies on the types of barriers developed in the realm of energy efficiency (Sorrell et al., 2004; Cagno et al. 2013), because no specific theory or taxonomy has been presented for barriers to load shift. In order to provide a step toward barrier taxonomies for load shift, the second research question is (Q2) which barriers to load shift can be grouped together and how does this grouping compare to the standard barriers to energy efficiency taxonomy?

As is the case for more general organizational adoption of innovations (Damanpour, 1991; Tornatzky and Klein, 1982), DeCanio and Watkins (1998) showed that firm characteristics also matter for adoption of energy innovations. Three characteristics of interest are the size of the organization, the strategic value of its energy management, and the type of production process. To test the relevance of these three company characteristics, we ask: (Q3) Do company characteristics matter for the perception of barrier relevance?

The remainder of the paper attempts to answer the three research questions. First, section 2 presents the research design and the methods used for data collection and analysis. In section 
3, the results of the statistical analyses are presented and discussed. Finally, in section 4, conclusions are summarized and implications for policy discussed.

\section{Data \& Method}

\subsection{Research design}

\subsubsection{Building on the energy efficiency barriers literature}

In this study, load shift is defined as a voluntary reduction or increase of a company's momentary electricity demand in response to incentives such as, for instance, bonus payments, transportation charges, and electricity rates (adapted from: US DoE, 2006). Engaging in load shift entails adaptation on the part of the energy user. It requires operational change and, in many cases, investments in technology and/or training (Kim and Shcherbakova, 2011; Torriti et al., 2010; VDE, 2012). The adaptation has many similarities to the adoption of energy efficiency measures. At the same time, as pointed out in the introduction, differences are many. Nevertheless, both are energy management innovations and both are likely evaluated by the same criteria. We thus assume that the well-developed energy efficiency barriers approach (e.g. Brown, 2001; DeCanio, 1998; Jaffe and Stavins, 1994; Sorrell et al., 2004; 2011; Cagno et al., 2013) can be used to explore barriers to load shift.

We draw on the widely used taxonomy of barriers that was first proposed by Sorrell et al. (2004). Its merit is its combining economic, behavioral, and organizational perspectives to derive an extensive set of barriers, which breaks out in six broad categories: imperfect 
information, hidden $\operatorname{costs}^{1}$, risk, access to capital, split incentives, and bounded rationality (Fleiter et al., 2012a; Sorrell et al., 2004). Sorrell et al. (2004) and Schleich (2009) offer extensive explanations of each category. The Sorrell et al. (2004) taxonomy has a theoretical basis and was intended to guide case studies, not survey-based empirical work. Nonetheless, the taxonomy has been helpful in survey design as well (Fleiter et al., 2012a; Rohdin et al., 2007; Schleich, 2009; Schleich and Gruber, 2008; Sorrell et al., 2004; Thollander et al., 2007; Thollander and Ottosson, 2008; Trianni and Cagno, 2012). Recently, Cagno et al. (2013) proposed an expanded taxonomy aimed at guiding empirical work. It adapts Sorrell et al.'s theory-based framework for empirical work and adopts a wider definition of barriers. According to Sorrell et al. (2004) "a barrier is a mechanism that inhibits a decision or behaviour that appears to be both, energy efficient and economically efficient. In particular, barriers are claimed to prevent investment in cost-effective energy efficient technologies." What is cost-effective is generally determined by engineering-economic assessments. It takes contextual factors (e.g., energy prices) as a given. Cagno et al. (2013), however, add barriers external to the firm that can explain why potentials remain unused even if firms adopt all measures that are both energy and economically efficient as in Sorrell et al's definition.

\subsubsection{Empirical setting}

This research was part of larger project to study the potential for and barriers to electricity load shift in German industry. Data was gathered through a one-time online survey among business sites of manufacturing firms in Southern Germany, i.e., in the Federal States named Bavaria and Baden-Württemberg. There, load shift is pertinent as supply side intermittency is

\footnotetext{
${ }^{1}$ The term "hidden" relates to the fact that these costs are typically unobservable to the outside observer. In this sense, costs are measured with error.
} 
growing fast due to the strong diffusion of solar-PV alongside the phase-out of all nuclear power by 2022 (Klobasa et al., 2014). Manufacturing firms represent a significant source of unused load shift potential (Hartkopf et al., 2012), and one where better familiarity with the concept promises better scale validity. Our level of analysis is the production site. Targeted sectors were food, timber, rubber and plastics, textile/fabrics, paper/publishing/printing, glass and ceramics, mining/minerals, chemicals, metals, electronics, machinery, and automotive. This multi-sector approach serves the exploratory purpose of this study, which aims to provide a stepping-stone toward more fine-grained empirical work. The survey was to generate cross-sectional data that would allow the univariate and bivariate analyses to answer research questions 1 and 3, and some simple multivariate analysis to answer research question 2.

The larger survey was organized in the following seven question block: (1) general questions about the company, (2) the company's pattern of electricity consumption, (3) load shift experience and technical potential, (4) economic potential and financial incentives, (5) drivers of and barriers to load shift, (6) experience and perception of security of energy supply, (7) and questions on the position and experience of the person responding.

\subsubsection{Barrier questions}

Our questions on barriers in part 5 of the survey are inspired by the Sorrell et al. (2004) taxonomy and on the barrier questions in the one survey on firm adoption of load shift in California (Quantum Consulting Inc., 2004). We also include contextual factors as proposed by Cagno et al. (2013). Moreover, similar to the analyses by Schleich and Gruber (2008), or Schleich (2009) for barriers to energy efficiency, we do not presuppose that load shift measures are profitable. Such an analysis would require high quality data resulting from indepth company- and measure-specific analysis. Instead, our survey includes items directly asking about the profitability of load shift measures. 
Compromising between being comprehensive and concise, 21 questions (items) on barriers were included in the larger project questionnaire (Table 1). The list intends to cover all theoretical aspects and present practical situations to the respondents. There is no item to survey bounded rationality (Simon, 1957), because it is difficult to find proxies for that can be used in a survey (Fleiter et al., 2012a; Simon, 2000). Table 1 lists the barriers ordered by category (see Cagno et al., 2013) and indicates whether the barrier's origin is internal or external to the organization, or possibly both if they depend on factors that are both within and external to the organization.

Insert Table 1 about here

For the barrier questions, a 5-point Likert scale was used, where respondents could indicate to which extent a barrier was relevant to them to not engage, or not engage more, in practicing load shift. Possible answers ranged from "not relevant at all" (1) to "very relevant" (5).

The survey captures perceived rather than real barriers. While conceptually perceived barriers may differ from real barriers, we follow the conceptual and empirical literature on innovation adoption (e.g. Rogers, 2003) and assume that perceptions explain behavior.

\subsection{Data collection}

Survey participants were reached through an announcement in the regular newsletter of the chambers of commerce of Bavaria and Baden-Württemberg, and direct invitations were emailed to several companies as well. Furthermore, members of the national association of industrial power plant operators (VIK) and of the regional association of large electricity 
consumers (GAV) in Baden-Württemberg were addressed. Members of the VIK are typically from the energy intensive industry and are expected to represent a substantial share of the demand response potential. Our sampling did not distinguish between firms practicing and firms not practicing load shift. In the introduction on the opening screen of the survey, it was asked that a company representative who is very familiar with the site's electricity use take the survey. To induce respondents to participate, to reduce hypothetical bias, and to foster accuracy and completeness, it was promised that upon completion of the survey the respondent would be presented an estimate of the potential gains from load shift for his/her company based on the responses provided. Also, respondents could opt to be communicated the survey results so as to be able to compare themselves to the average of the other participants completing the survey.

The survey was self-administered and available online between March 11 and April 30, 2013. Participants could decide themselves when to fill out the survey and they had the option to abort, or to stop and continue later anytime.

A total of 287 responses were recorded, many of which incomplete. No question got more than 177 valid answers. As it cannot be known who exactly received or learned about the survey, a meaningful response rate cannot be determined. The time respondents spent on the survey varied widely. Of the 185 participants who spent one minute or more on the survey the average time spent was 19.2 minutes.

Sites in Bavaria or Baden-Württemberg accounted for 81 percent of the responses .The majority of the rest ( 9 percent) was from North Rhine-Westphalia, which were mainly members of the national association of industrial power plant operators. They were included to get a better representation of energy intensive industries. Sectors that accounted for 5 or more percent of the respondents were metals $(17 \%)$, chemicals $(11 \%)$, food $(7.3 \%)$, 
paper/publishing/printing $(7.3 \%)$, rubber and plastics $(5.6 \%)$, glass ceramics $(5.6 \%)$, machinery (5.1\%), and electronics (5.1\%).

Except for the $44 \%$ of respondents with a standard contract ("Vollversorgung"), all other companies had some incentive to shift loads (i.e., they were subject to dynamic pricing). Only $2 \%$ said they had bilateral load shift agreements with the grid operator and only $4 \%$ considered themselves participants in the grid-balancing market. Nearly half $(47 \%)$ of the respondents used load shift for internal purposes only, while $41 \%$ had no experience with load shift.

The questions on the barriers appeared toward the end of the survey. The order in which they were presented was randomized so as to prevent order bias. The number of valid responses per barrier varied between 63 and 83. In 48 cases valid responses were received for all 21 barrier questions.

\subsection{Data analysis}

The survey yielded cross-sectional data with, in addition to barrier scores, firm attributes and patterns of energy use. In our analysis, we first univariately ranked all 21 barriers by stated importance. Second, we employed principal component analysis to find a natural grouping of barriers from the user-firm perspective. Third, we used the principal component factor scores to assess the effect of barriers on reported load shift potential in an ordered logit regression. Finally, we assessed the influence of firm characteristics by bivariately comparing means of split samples. The descriptive statistics of the variables used are presented in Table 2. 


\subsubsection{Ranking of barriers}

To analyze which barriers are generally considered most important, we ranked the barriers by importance. The ranking is based on adding the share of respondents rating a barrier 'relevant' (4) and the share rating it 'very relevant' (5).

\subsubsection{Principal component analysis}

We used principal component analysis to see if there was an underlying structure to the 21 barrier items. While this data is ordinal, for the purpose of this exploratory research and as is common in social sciences (and also in barriers to energy efficiency) research (e.g., Fleiter et al., 2012a; Trianni et al., 2013a), we assume that the points on the scale are equidistance and the data can be interpreted as interval. The analysis included the 48 cases with valid responses to all barrier items to find clustering of barriers that potentially hints at deeper, underlying factors. Even though the number of cases is relatively low, the analysis was deemed worthwhile, considering the exploratory purpose of this research.

\subsubsection{Ordered logit regression of load shift potential on barrier factor scores}

We used the factor scores coming out of the principal component analysis to estimate the effect of the principal barrier components on the reported load shift potential. The latter is the dependent variable, which was measured by the following question (our translation from German): What is the highest estimated possible load you can technically shed at your production site when production is running normally? The respondents could select one of the following ranges: $<2 \%, 2-3 \%, 4-6 \%, 7-10 \%, 11-15 \%,>15 \%$. The categories were coded 1 to 6. This question yielded ordinal data, so we employed an ordered logit model to regress the potential on the barrier components. The estimated model looks as follows:

(1) Load shift potential category $=\beta_{0}+\beta$ FACTORS $+u$, 
where $\beta$ is the (row) vector of slope coefficients, FACTORS is the (column) vector of factor scores for the extracted components, and $\mathrm{u}$ is the usual error term.

\subsubsection{Bivariate analyses on relations between barrier perception and company characteristics}

We explored the relations between the barriers and company characteristics bivariately. To do so, we compared the mean barrier scores in two-sided t-test for a set of six company characteristics, each corresponding to one of the three relationships of interest (size, strategic value of energy, production process). As proxies for size we used the number of employees at the organization level (across all sites) and the organization's turnover. We split the sample at the median of all valid values for employees and turnover, respectively. As proxies for strategic value of energy we used the energy intensity (calculated by the ratio of the annual electricity consumption and annual turnover of the site for 2012), the absolute normal electric load, and the electricity expenditures. The samples were again split by the median. For the production process, we distinguished batch, just-in-time, and continuous production and compared each of them to the other two. As some companies used multiple production process types, this means that we compared those who used only the production process in focus to those who did not use this process. The t-tests allow exploration of the potential relations between perceptions of barriers (specific barriers and barriers in general) and company characteristics, which may guide more in-depth future research.

Insert Table 2 about here 


\section{Results and discussion}

\subsection{Ranking of barriers}

Figure 1 shows the findings of respondents' assessment of barrier relevance per barrier item.

Insert Figure 1 about here

Several things stand out. First, near the top of the graph are several barriers that indicate that interference with the core business processes and products is of major concern: technical risk of disruption of the production process, risk of lower product quality, and disruption of operations. Respondents seem to have reservations about the compatibility of load shift programs with core business operations, or there is little willingness to accept interference with core processes. Recalling that few respondents had prior experience participating in load shift schemes, this perception is probably hypothetical and a reflection of priorities rather than based on experience. Second, immediately following the interference barriers, financial and regulatory certainty rank high on the list of barriers. Barriers include unknown future regulations, restrictive regulatory framework, low electricity cost savings, uncertain cost savings, additional operating costs, complex regulatory framework, unknown financial implications, and cost savings too far into the future. This last one ranks lower, hinting that it is more important to know the what rather than the when of financial and regulatory conditions. Third, access to capital is hardly perceived as a relevant barrier. Fourth, lack of qualified personnel and data security are relatively unimportant as well. 
The top-ranking barriers are in agreement with the results from the California survey (Quantum Consulting Inc., 2004). In California, inability to reduce peak loads was an important barrier, too. In our study it ranks lower, although it is a more polarized barrier, with relatively many extreme ratings ( 5 and 1 on the Likert scale). Barriers related to financial and regulatory risk take up most of our medium range barriers. Although lack of knowledge and cost of technology may be key barriers to slow diffusion of load shift (programs) (Kim and Shcherbakova, 2011; Torriti et al., 2010), we find no evidence for 'lack of information' being an important barrier in our sample; cost of technology (investment costs) is fairly important, though.

In general, our findings are consistent with the scant literature on diffusion of load shift in that, on the energy user side, risk and hidden costs constitute the most important barriers to load shift diffusion in industry. Our results hint at considerable reservation about load shift among manufacturers. If load shift were to interfere with core processes or product quality, little willingness will likely remain to participate in load shift programs.

\subsection{Principal components underlying the 21 barrier items}

The principal component analysis, conducted to explore if a structure underlying the 21 barrier items could be revealed, returned five factors with eigenvalue greater than 1 (Kaiser criterion). These five factors explain 68 percent of the total variance. Varimax rotation was applied to maximize dispersion of loadings within the factors and yield the clearest distinctions between factors possible. The rotated component matrix with resulting factor loadings is shown in Table 3. 
Insert Table 3 about here

In Table 3, the factor scores above 0.5 are highlighted (boldface). Using 0.5 as the cut-off value, nine factors load highly on factor 1 . They all seem to relate to negative consequences for firm financial planning and can be labeled 'financial and regulatory risk'. The four barriers that load highly on the second factor relate to interference with the core processes and products. These represent 'technical risk' and comprise the barriers that were perceived as most relevant as well (see Figure 1) plus 'technically infeasible to reduce peak load.' The third factor is made up of the availability of financial (access to capital) and technical options, which we will label 'knowledge of and access to options.' Factor four represents the low priority given to energy management. We label this 'internal issue prioritization.' The fifth factor seems to refer to lack of skills only, although it is clouded considerably by the influence from other barriers. For the time being we label this factor 'competences.' The items data security and additional workload are complex variables; they do not load highly on any of the factors but have their loadings spread out across several. It may indicate that these constitute composite or derived concerns operating at a different level. Cronbach's $\alpha$ for factors one to four are $0.870(N=51), 0.801(N=74), 0.720(N=60)$, and $0.667(N=78)$, respectively, which is acceptable for the purpose of this study. ${ }^{2}$

Of the complex items (i.e., those not well captured by the factors) data security is a barrier that is "very relevant" to hardly any of the respondents and ranks low in Figure 1. Additional

\footnotetext{
${ }^{2}$ Since factor five (competences) is a single-item factor, no $\alpha$ can be determined.
} 
workload, on the other hand, is ranked much higher as a barrier, and cannot just be ignored because it does not load highly on any factor.

These results show that, in the context of load shift, respondents perceive financial and regulatory risk separately from technical risk. Fleiter et al. (2012a) come to a similar conclusion for energy efficiency measures. Second, lack of knowledge of the options, a form of imperfect information, and access to capital seem to combine into a broader category of access to means in a more generic sense, not only financial. The barriers making up this category may represent initial hurdles that are external to the site's energy manager and that may come before specific load shift measures are evaluated and thus may have been used by respondents as justifications for inaction. Energy not being a priority was expected to closely relate to lack of access to internal capital, but these two barriers seem rather independent. This may be due to the early stage load shift is in. With the little load shift experience the manufacturing firms currently have, for many of them it may be too early to judge investments as long as uncertainty about regulations, incentives and potential implications is high. Capital concerns will probably become more salient when decisions to adopt or not adopt are pertinent. Third, lack of employee skills represents a separate category. In the Sorrell et al. (2004) framework this would be a 'hidden cost,' but it is consistent with Cagno et al. (2013), who choose to have a separate category related to competences. It has been shown before (Thollander et al., 2007; Trianni and Cagno, 2012) that from a practitioner's perspective, especially in SMEs, lack of expertise and competences to identify opportunities and implement measures are direct barriers to adoption. One could expect that 'lack of employee skills' loads on the same factor as 'technological options unknown,' as they could both represent some lack of capability, but they do not. This separation supports Cagno et al.'s (2013) distinction of the two barriers, which is motivated by the idea that perception of unavailability of technologies can be due to such factors as their low diffusion or the lack of 
interest by technology suppliers, both of which are external and not related to competences. It may be speculated that companies finding 'lack of employee skills' a relevant barrier may be looking inward for barriers; they may be further ahead with load shift evaluation than those who rate highly initial hurdles that are mostly external to their responsibility. It should be kept in mind though, that 'access to internal/external capital,' 'technological measures unknown,' and 'lack of employee skills' rank at the bottom when it comes to perceived relevance. Fourth, the complex items 'additional workload' and 'data security' seem clear hidden cost items, but they spread out across multiple factors. It shows that, from a practitionerrespondent's perspective, hidden costs is a very heterogeneous category with cost factors that are quite independent of each other but may overlap with barriers in other categories (e.g., imperfect information can mean higher search costs).

In sum, for most items considered, the clustering suggested in Sorrell et al. (2004) seems to also fit load shift barriers as do the adaptations suggested by Cagno et al. (2013). From this perspective the literature on barriers to energy efficiency appears valuable for conceptualization and guiding research on barriers to load shift. Nevertheless, and similar to Fleiter at al. (2012a) or Cagno et al. (2013) for energy efficiency measures, we observe that the barrier items as clustered in Sorrell et al. (2004) do not always appear together, and a refinement and reorientation of the barrier categories may be called for when carrying out survey-based empirical analyses.

\subsection{Ordered logit regression on the relation between load shift potential and principal barrier components}

The ordered logit estimation for the relation between reported load shift potential and barrier components prompted to collapse the highest two categories of the dependent variable as cut- 
off points 4 and 5 were not statistically significantly different $\left(\operatorname{Chi}^{2}(1)=2.99, p<0.084\right)^{3}$. With five categories remaining, though, still only the coefficient for the technical risk component is significant $(p<0.05)$ (see results in Table 4).

Insert Table 4 about here

This result suggests that perceived technical risk is important enough to significantly and negatively affect the reported potential while no such effect is found for the other barrier components. This result supports the results from the ranking of barriers in section 3.1.

The odds ratio for technical risk indicates that a one standard deviation difference in the technical risk factor score means a factor 0.45 difference in the odds of reporting a certain load shift potential category compared to any lower category (e.g. $>10 \%$ compared to $10 \%$ or lower). The average marginal effects for the highest $(>10 \%)$ and lowest potentials $(<2 \%)$ are 0.102 and 0.142 , respectively. It means that probability that the reported load shift potential is $>10 \%$ decreases by 10.2 percentage points on average for one standard deviation increase of technical risk factor score. Inversely, the same factor score change increases the probability that the reported load shift potential is $<2 \%$ by 14.2 percentage points.

\subsection{Relations between barriers and company characteristics}

In this section we discuss the statistically significant results of the two-sided t-tests conducted to explore effects of company characteristics on barrier perception.

\footnotetext{
${ }^{3}$ We also tested the so-called parallel lines assumption and found no evidence that it is violated.
} 


\subsubsection{Company size}

For both the number of employees and the turnover proxy of firm size, t-tests with none of the barriers yielded results that were significant at the 5\% level. We did not find a barrier that smaller firms rated statistically significantly higher than larger firms. Thus, barrier perception does not appear to be related to firm size in our sample, which has considerable variance in firm size but contains few SMEs.

We expected larger firms to report lower barriers to load shift adoption, because larger firms are generally more innovative (Damanpour, 1992). Size promotes more structural complexity, formalization, and decentralization, as well as the availability of resources (Ettlie et al., 1984; Kimberly and Evanisko, 1981; Schleich, 2009), which are positively related to firms' innovation adoption behavior (Aiken and Hage, 1971; Damanpour, 1996). Also, it has been shown previously that small businesses face considerable difficulty accessing capital for energy efficiency measures (e.g. Trianni and Cagno, 2012; Trianni et al., 2013b). Access to capital may be less important for adopting load shift measures compared to energy efficiency measures if the former mainly involve organizational and other low-cost measures.

\subsubsection{Strategic value of energy}

Our results for the proxy variables for the strategic value of energy (electricity use, expenditures and intensity) are summarized in Table 5. Companies with high normal electric load show more concern about 'uncertain electricity cost savings,' but we do not find electricity intensity having an effect on this concern. More electricity intensive companies, however, report higher scores for 'regulations too restrictive,' which companies with higher electricity expenditures do as well. The latter show more concern than companies with lower electricity expenditures about regulatory uncertainty, too, but this difference is not found for more and less electricity intensive companies. 'Electricity expenditures' is the only variable 
for which a significant effect on concern about regulatory uncertainty is found. Companies with higher electricity bills rate 'additional operating costs' higher, too.

Insert Table 5 about here

The result that both absolute and relative electricity use matter for the importance of financial and regulatory risk is consistent with the literature on energy efficiency barriers, where higher energy costs usually yield higher perception of barriers (Trianni et al., 2013a). However, in our case it applies to perception of risk barriers specifically, especially about regulations. For more energy intensive firms, load shift regulations are more likely to affect a firm's willingness to engage.

For electricity intensive companies access to options, both financial and technological, is of relatively little concern. However, we did not find evidence that electricity intensive firms are generally more inclined to adopt load shift, which the literature is undecided about. It has been shown that a higher cost-share of electricity suggests higher strategic relevance of energy innovations (Cooremans, 2011) and that this is more important a criterion for energy efficiency investment decisions than financial profitability (Cooremans, 2012; 2011). Therefore, in analogous fashion, more energy intensive electricity users should be more inclined to adopt load shift. On the other hand, electricity intensity also suggests that electricity is an important production factor and electricity intensive companies may therefore value quality of electricity more than do less electricity intensive businesses (Kim and Shcherbakova, 2011), which would constitute a counter-effect. Indeed, it was shown that even for the largest customers of Niagara Mohawk Power Corporation in New York State price 
response is low (Hopper et al., 2006). These two sides need not be contradictory; despite adoption of load shift, actual response can still be low. A possible explanation is that for energy intensive companies electricity is so important that it reduces the willingness to take risks, whereas they would be interested if tested cost-saving options were available.

\subsubsection{Production process}

In addition to the energy intensity of the production process, its organization (whether production is just-in-time (JiT), batch-wise, or continuous) could be expected to affect load shift adoption decisions. Load shift likely affects the production process and its planning. Indeed, our results for the effect of the type of production process (Table 6) show a rather large difference between those who produce in batches compared to those who do not when it comes to concerns about 'interference with personnel planning.' The reverse is found when comparing companies with a continuous production process to non-continuous producers, but no significant difference is found for companies with just-in-time production compared to others. For all barriers except one, companies with a continuous production process make up half or more of the sample. Across the board they rank barriers lower than companies with a batch and/or just-in-time process. Significant differences are found for the average score of all barriers and the specific barriers 'technical risk of disruption of the production process,' 'potential negative impact on product quality,' 'additional workload,' and 'energy management not a priority of top management.' This last barrier appears to be particularly relevant in companies with just-in-time production, but not in those who produce in batches.

Insert Table 6 about here 
These results may offer some guidance for which particular companies to target to promote load shift. Those who use a batch production process are especially concerned about interference of load shift with their process planning, possibly because batch production is applied in more time-sensitive, order-driven processes, which are less flexible on very short time periods. This limited flexibility also applies to just-in-time producers, where shifts in load likely ripple through the supply chain and affects closely coordinated logistical planning. Many just-in-time producers in our sample are related to the automotive industry, where production processes are linked together. Additional interference to the production process can lead to high costs when the supply chain and supply commitments are delayed. The complex logistical challenge of the just-in-time producers could explain why for them 'energy management is not a priority for top management' is more important barrier than for others. In other words, opportunity costs for batch and just-in-time producers are higher and, therefore, they both rate barriers more highly across the board than do firms with a continuous production process. It may seem a counterintuitive because continuous processes seem less flexible as they have been designed for the purpose of uninterrupted production - interruption often causes loss of product and product quality. However, this vulnerability to interruptions constitutes a powerful incentive for continuous producers to install safety measures (e.g., selfgeneration) to mitigate this risk of power supply irregularities (Grünewald and Torriti, 2013). These companies could leverage these measures to minimize energy costs through load shift as well. Indeed, a study among Californian industry found that firms with continuous production did not participate less in load shift programs than firms with batch production (Ghatikar et al., 2012). This explanation, though, seems at odds with what Trianni et al. (2013b) found for barriers to energy efficiency measures among Italian primary metal manufacturing SMEs, where companies with little variability of production and demand have higher barriers to adoption of energy efficiency measures. This difference may be a 
manifestation of the different nature of energy efficiency measures and load shift as innovations, or due to the fact that our samples contains very few SMEs, which may be less likely to have invested in back-up generation.

\subsection{Limitations and future research}

Limitations of this study, which merit further study, are the following. First, as is common in empirical analysis relying on company surveys our sample size is relatively small, in particular when compared to analyses employing household level data. Thus, the sample size in our analysis may limit the robustness of our findings and underlines the exploratory nature of our study. Especially, the limited number of observations and the variation in sectors and firm sizes are caveats for more complex, multivariate analyses that take into account sufficient confounding factors. However, the results of this exploratory study justify further research on barriers to load shift adoption with larger samples sizes, which could test if our findings hold in multivariate settings. Such analyses would then allow for a more detailed statistical assessment of the impact of company attributes, technology characteristics or policy variables on load shift adoption and barriers.

Second, our data, and that in much of the empirical work on barriers to energy efficiency, concerns perceived barriers rather than real barriers. Real barriers pose many measurement problems and perceptions are driving behavior; however, the difference between real and perceived barriers is relevant for policy making when there is discrepancy between them. For instance, firms may state that access to external capital is a barrier while very few have actually applied for outside funding (Cooremans, 2012:508). Such discrepancies deserve more scholarly attention.

Third, the behavioral barriers in this study focus on cognitive, managerial aspects related to the decision to adopt. The choice of method prevented the inclusion of bounded rationality, 
likely a relevant barrier in the context of this study. Other aspects of behavior may act to hinder implementation of load shift, such as resistance to change of those operating the units. This resistance may be rooted in psychological, cultural and organizational factors. Preference for the status quo can be a real barrier to implementation and a real or perceived barrier to adoption (Sorrell et al., 2011). We encourage future research to distinguish the decision to adopt from implementation (cf. Rogers, 2003) and take into account attitudinal barriers.

\section{Conclusions and policy implications}

In this paper, we explore barriers to firms' adoption of load shift based on an online survey among manufacturing sites located primarily in Southern Germany. Our first research question asked which barriers are relevant. We found that the most important barriers are risk of disruption of operations, impact on product quality, and uncertainty about cost savings. Of little concern were access to capital, lack of employee skills, and data security. The multivariate analysis confirmed the importance of technical risk.

The findings of our principal component analysis respond to the second research question, which asked which barriers appear together. The results suggest that financial and regulatory uncertainties are perceived jointly and are separate from technical risk. Other distinct factors are the knowledge of and access to load shift options, the priority of energy within the firm, and the lack of adequate competences.

Our third research question asked if company characteristics affect the rating by firms of barrier relevance. The results of two-sided t-tests suggest that companies for which electricity has higher strategic value appear more concerned about technical, financial and regulatory risk. Companies with a continuous production process report lower barrier scores than companies using batch or just-in-time production. For just-in-time producers, energy is less a priority. 
Several policy implications emerge from our analysis. The widespread concern about interference with core processes and product quality may imply that increased potential comes at increased marginal risk as the load shift comes progressively closer to the core production process. This means that the savings from saved peak energy costs are increasingly less sufficient an incentive for the firm to shift load. The transfer of risks from the grid operator to the energy user could be built into load shift incentive programs to exploit more of the potential.

Furthermore, the concern for interference with the core process and products may suggest that although load shift may spread widely, policy makers should not count on deep exploitation of what engineering-economic assessments suggest is the viable potential. Although policy makers may ogle the seemingly large potentials at energy-intensive firms, higher rates of exploitation may be achieved at energy extensive firms and in auxiliary systems. The fruit may not seem so large but may hang lower at the many smaller electricity consumers. On the other hand, due to the lower priority of energy in energy extensive firms, it might be more difficult to activate these smaller potentials. The concern for interference with core processes may be mitigated through demonstration projects and case studies that demonstrate that the real technical risk is lower than thought.

The finding that financial and regulatory uncertainties are perceived jointly implies that without incentive structures in place, without awareness thereof, or without confidence in them, firms cannot evaluate load shift practices and decide on their adoption. Program design, communication and diffusion precede load shift adoption by energy using companies. Implementation of clear, simple, and flexible conditions is a likely prerequisite for load shift to spread among energy using firms. Then, more specific barriers can be expected to become manifest and will it make sense to address these. Therefore, research should address barriers to load shift program diffusion, too, and include actors on the supply side (Cappers et al., 
2013). A key question is who is responsible to push and finance such response programs, as this inevitably involves multiple entities and requires coordinated action in the electricity supply chain (Greening, 2010).

For the more energy intensive firms, or if core processes are involved, on top of an adequate incentive structure, there may be a need for additional policy instruments or services that provide insurance against unexpected, negative conditions, such as when a grid emergency requires load to be shifted but comes at a time when the company coincidentally has no flexibility and would incur large opportunity costs if it were to shift load (e.g., failure of production equipment). Some backup capacity may need to remain in the system to insure against unfortunate combinations of events. Also, the aggregate of load shift capacities that are combined in a pool should exceed by some margin what that pool offers on the balancing market.

The result that firms with continuous production perceive lower barriers than firms with batch and/or just-in-time production could mean that firms with continuous production processes have insurance measures against power interruptions built in already. Such insurance measures (e.g., on-site backup generation) shield against excessive opportunity costs of load shift and increase flexibility compared to batch and just-in-time processes. Therefore, although unlikely candidates at first thought, firms with continuous production may represent a category where policy makers may find some low-hanging fruit. However, if such safety measures boil down to on-site backup generators (Grünewald and Torriti, 2013), which often use natural gas, it is clear that load shift capacities may not have the same environmental quality.

This consideration shows that, a priori, it cannot be taken for granted that the contribution of load shift to a cleaner, more reliable and more efficient electricity supply will be positive and 
should be assessed in sufficient detail. Several additional potentially antagonistic effects between load shift and energy efficiency can occur. For instance, load shift leads to peak shaving, having a disproportional effect on average energy prices and thus on incentives for investing in energy efficiency measures. Also, the effect of some energy efficiency measures, such as of efficient lighting, may be concentrated during peak hours. These measures affect the shape of the load curve, but do not shift the load. Under load shift incentives load shift capacity represents value, which can add to the opportunity costs of investing in energy efficiency measures. The two are in competition. The question is which conditions are needed to yield the best outcome from a societal perspective. The coordination of policy goals and instruments (in this case energy efficiency and load shift) and system levels deserve the attention of scholars (Goldman et al., 2010). Policy-making and research should address load shift in conjunction with energy efficiency under the heading "energy management," thus widening the scope of the label as proposed by Backlund et al. (2012).

\section{Acknowledgments}

The study was conducted by the Fraunhofer Institute for System and Innovation Research and Forschungsgesellschaft für Energiewirtschaft on behalf of Agora Energiewende, in cooperation with the environmental ministries of Baden-Württemberg and Bavaria. We thank Gerhard Angerer and Corinne Faure for their contribution in designing and conducting the survey. 


\section{References}

Aiken, M., Hage, J., 1971. The organic organization and innovation. Sociology 5, 63-82.

Backlund, S., Thollander, P., Palm, J., Ottosson, M., 2012. Extending the energy efficiency gap. Energy Policy 51, 392-396.

Baritaud M., Securing power during the transition, IEA Insights Ser. 2012, Paris: International Energy Agency, 2012.

Borenstein, S., 2005. The long-run efficiency of real-time electricity pricing. Energy J. 26, 93-116.

Brown, M.A., 2001. Market failures and barriers as a basis for clean energy policies. Energy Policy 29, 1197-1207.

Cagno, E., Worrell, E., Trianni, A., Pugliese, G., 2013. A novel approach for barriers to industrial energy efficiency. Renew. Sustain. Energy Rev. 19, 290-308.

Cappers, P., MacDonald, J., Goldman, C., Ma, O., 2013. An assessment of market and policy barriers for demand response providing ancillary services in U.S. electricity markets. Energy Policy 62 (C), 1031-1039.

Cooremans, C., 2011. Make it strategic! Financial investment logic is not enough. Energy Efficiency 4, 473-492.

Cooremans, C., 2012. Investment in energy efficiency: do the characteristics of investments matter? Energy Effic. 5, 497-518.

Damanpour, F., 1991. Organizational innovation: a meta-analysis of effects of determinants and moderators. Acad. Manag. J. 34, 555-590.

Damanpour, F., 1992. Organizational size and innovation. Organ. Stud. 13, 375-402.

Damanpour, F., 1996. Organizational complexity and innovation: developing and testing multiple contingency models. Manag. Sci. 42, 693-716. 
DeCanio, S.J., 1998. The efficiency paradox: bureaucratic and organizational barriers to profitable energy-saving investments. Energy Policy 26, 441-454.

DeCanio, S.J., Watkins, W.E., 1998. Investment in energy efficiency: do the characteristics of firms matter? Rev. Econ. Stat. 80, 95-107.

Delmas M.A. and Pekovic S., Resource efficiency strategies and market conditions, Long Range Plan. 2014, Available online 27 September 2013, ISSN 0024-6301, http://dx.doi.org/10.1016/j.lrp.2013.08.014, in press.

Ettlie, J.E., Bridges, W.P., O'keefe, R.D., 1984. Organization strategy and structural differences for radical versus incremental innovation. Manag. Sci. 30, 682-695.

Faruqui, A., Hledik, R., Newell, S., Pfeifenberger, H., 2007. The power of 5 percent. Electr. J. $20(8), 68-77$.

Faruqui, A., Palmer, J., 2011. Dynamic pricing and its discontents. Regulation, 16-22.

Fleiter, T., Schleich, J., Ravivanpong, P., 2012a. Adoption of energy-efficiency measures in SMEs - an empirical analysis based on energy audit data from Germany. Energy Policy 51, 863-875.

Fleiter, T., Hirzel, S., Worrell, E., 2012b. The characteristics of energy-efficiency measures a neglected dimension. Energy Policy 51 (C), 502-513.

GEA, 2012. Global Energy Assessment-Toward a Sustainable Future. Cambridge University Press, Cambridge, UK and New York, NY, USA and the International Institute for Applied Systems Analysis, Laxenburg, Austria.

Ghatikar, G., McKane, A., Goli, S., Therkelsen, P., Olsen, D., 2012. Assessing the Control Systems Capacity for Demand Response in California Industries (No. LBNL-5319E). Ernest Orlando Lawrence Berkeley National Laboratory, Berkeley, CA. 
Goldman, C., Reid, M., Levy, R., Silverstein, A., 2010. Coordination of Energy Efficiency and Demand Response (No. LBNL-3044E). Ernest Orlando Lawrence Berkeley National Laboratory, Berkeley, CA.

Greening, L.A., 2010. Demand response resources: who is responsible for implementation in a deregulated market? Energy J. 35, 1518-1525.

Grein, A., Pehnt, M., 2011. Load management for refrigeration systems potentials and barriers. Energy Policy 39, 5598-5608.

Grünewald, P., Torriti, J., 2013. Demand response from the non-domestic sector: Early UK experiences and future opportunities. Energy Policy 61, 423-429. http://dx.doi.org/10.1016/j.enpol.2013.06.051.

Hartkopf, T., Scheven, von, A., Prelle, M., 2012. Lastmanagementpotenziale der stromintensiven Industrie zur Maximierung des Anteils regenerativer Energien im bezogenen Strommix. Technische Universität Darmstadt, Forschungsgruppe Regenerative Energien, Darmstadt, Germany.

Hopper, N., Goldman, C., Bharvirkar, R., Neenan, B., 2006. Customer response to day-ahead market hourly pricing: choices and performance. Util. Policy 14, 126-134.

IEA, 2012. World Energy Outlook 2012. International Energy Agency, Paris.

IEA, 2014. Technology Roadmap Solar Photovoltaic Energy, 2014 edition. International Energy Agency, Paris.

Jaffe, A.B., Stavins, R.N., 1994. The energy-efficiency gap. What does it mean? Energy Policy 22, 804-810.

Joskow, P.L., 2012. Creating a smarter U.S. electricity grid. J. Econ. Perspect. 26, 29-48.

Kim, J.-H., Shcherbakova, A., 2011. Common failures of demand response. Energy J. 36, 873-880. 
Kimberly, J.R., Evanisko, M.J., 1981. Organizational innovation: the influence of individual, organizational, and contextual factors on hospital adoption of technological and administrative innovations. Acad. Manag. J. 24, 689-713.

Klobasa, M., Angerer, G., Lüllmann, A., Schleich, J., Buber, T., Gruber, A., et al., 2014. Load Management as a Way of Covering Peak Demand in Southern Germany (No. 040/04S-2014/EN). (N. Bock). Agora Energiewende, Berlin, Germany.

Paulus, M., Borggrefe, F., 2011. The potential of demand-side management in energyintensive industries for electricity markets in Germany. Appl. Energy 88 (2), 432-441.

Quantum ConsultingInc., 2004. Working Group 2 Demand Response Program Evaluation Nonparticipant Market Survey Report. Quantum Consulting Inc., Berkeley, CA, pp. $1-129$.

Rogers, E.M., 2003. Diffusion of Innovations, 5th Edition Simon and Schuster, New York, NY.

Rohdin, P., Thollander, P., Solding, P., 2007. Barriers to and drivers for energy efficiency in the Swedish foundry industry. Energy Policy 35, 672-677.

Schleich, J., 2009. Barriers to energy efficiency: a comparison across the German commercial and services sector. Ecol. Econ. 68, 2150-2159.

Schleich, J., Gruber, E., 2008. Beyond case studies: barriers to energy efficiency in commerce and the services sector. Energy Econ. 30, 449-464.

Simon, H.A., 1957. Models of Man: Social and Rational. Wiley, Oxford, England.

Simon, H.A., 2000. Bounded rationality in social science: today and tomorrow. Mind Soc. 1, $25-39$.

Sorrell, S., O’Malley, E., Schleich, J., Scott, S., 2004. The Economics Of Energy Efficiency. Edward Elgar Pub, Cheltenham. 
Sorrell, S., Mallett, A., Nye, S., 2011. Barriers to industrial energy efficiency: A literature review. United Nations Industrial Development Organization, Vienna, Austria (Working paper no. 10/2011).

Thollander, P., Danestig, M., Rohdin, P., 2007. Energy policies for increased industrial energy efficiency: evaluation of a local energy programme for manufacturing SMEs. Energy Policy 35, 5774-5783.

Thollander, P., Ottosson, M., 2008. An energy efficient Swedish pulp and paper industry exploring barriers to and driving forces for cost-effective energy efficiency investments. Energy Effic. 1, 21-34.

Tornatzky, L.G., Klein, K.J., 1982. Innovation characteristics and innovation adoptionimplementation: a meta-analysis of findings. IEEE Trans. Eng. Manag. 29 (1), 28-45.

Torriti, J., Hassan, M.G., Leach, M., 2010. Demand response experience in Europe: policies, programmes and implementation. Energy J. 35, 1575-1583.

Torriti, J., Grünewald, P., 2014. Demand side response: patterns in Europe and future policy perspectives under capacity mechanisms. Econ. Energy Environ. Policy 3 (1), 69-87.

Trianni, A., Cagno, E., 2012. Dealing with barriers to energy efficiency and SMEs: some empirical evidences. Energy J. 37, 494-504.

Trianni, A., Cagno, E., Worrell, E., Pugliese, G., 2013a. Empirical investigation of energy efficiency barriers in Italian manufacturing SMEs. Energy J. 49, 444-458.

Trianni, A., Cagno, E., Worrell, E., 2013b. Innovation and adoption of energy efficient technologies_An exploratory analysis of Italian primary metal manufacturing SMEs. Energy Policy 61, 430-440.

US DoE, 2006. Benefits of Demand Response in Electricity Markets and Recommendations for Achieving Them. United States Department of Energy. 
VDE, 2012. Ein notwendiger Baustein der Energiewende: Demand Side Integration. VDE Verband der Elektrotechnik Elektronik Informationstechnik e.V., Frankfurt am Main, Germany.

Worrell, E., Laitner, J.A., Ruth, M., Finman, H., 2003. Productivity benefits of industrial energy efficiency measures. Energy 28 (11), 1081-1098. 
Figure 1 - Barriers to load shift (in \% of responses) ordered by perceived relevance based on the share of respondents rating a barrier "relevant" (4) or "very relevant" (5).

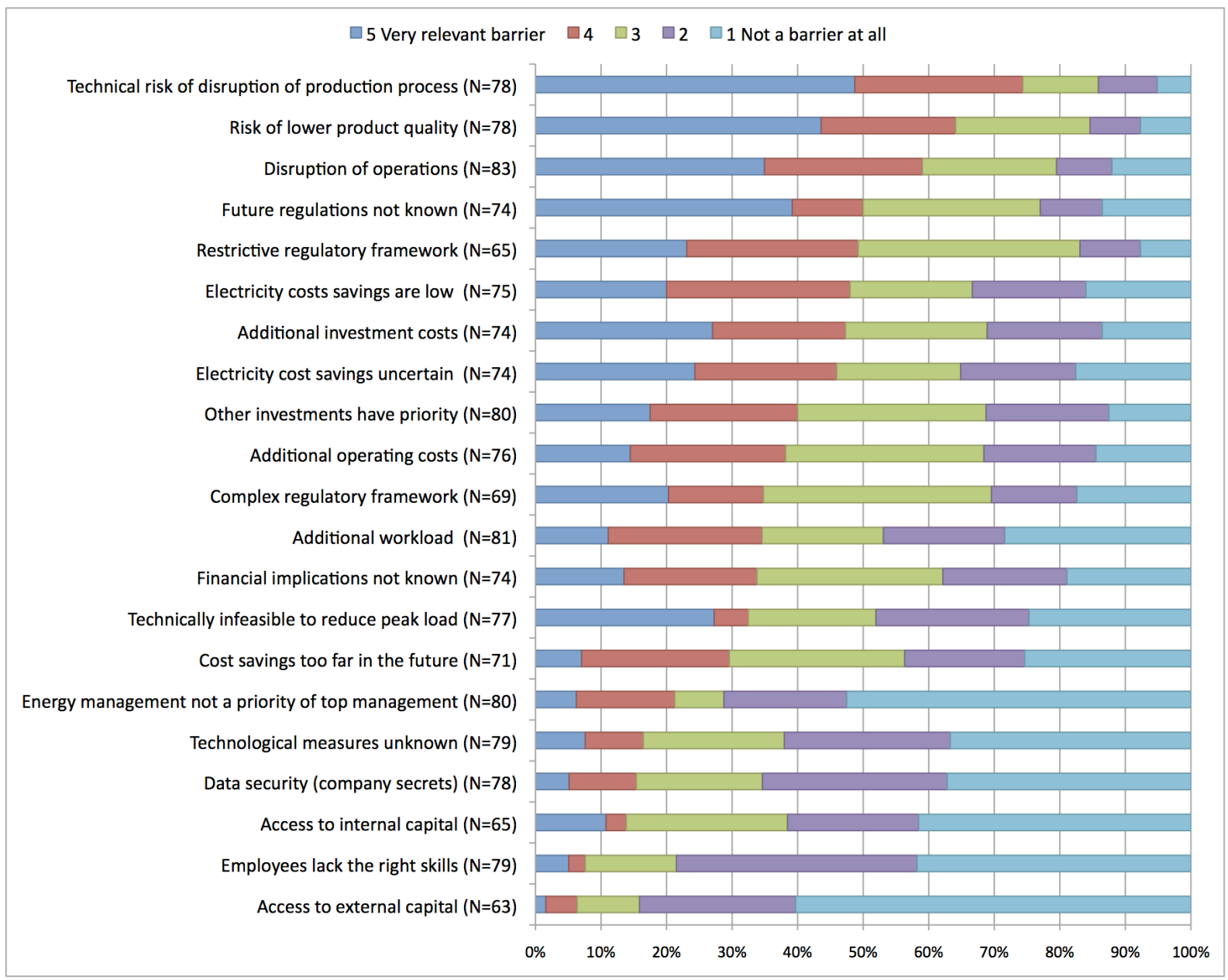


Table 1 - Barriers to load shift included in the questionnaire, categorized

\begin{tabular}{|c|c|c|}
\hline Category & Barrier items in the questionnaire & $\begin{array}{l}\text { Origin: } \\
\text { Internal/ } \\
\text { External }\end{array}$ \\
\hline Technological & $\begin{array}{l}\text { Technological measures unknown } \\
\text { Technically infeasible to reduce peak load } \\
\text { Technical risk of disruption of the production process } \\
\text { Risk of lower product quality } \\
\text { Data security (company secrets) }\end{array}$ & $\begin{array}{c}\mathrm{I} / \mathrm{E} \\
\mathrm{I} \\
\mathrm{I} \\
\mathrm{I} \\
\mathrm{E}\end{array}$ \\
\hline Information & $\begin{array}{l}\text { Electricity cost savings uncertain } \\
\text { Financial implications not known }\end{array}$ & $\begin{array}{l}\mathrm{E} \\
\mathrm{E}\end{array}$ \\
\hline Regulatory & $\begin{array}{l}\text { Future regulations not known } \\
\text { Restrictive regulatory framework } \\
\text { Complex regulatory framework }\end{array}$ & $\begin{array}{l}E \\
E \\
E\end{array}$ \\
\hline Economic & $\begin{array}{l}\text { Electricity cost savings are low } \\
\text { Cost savings too far in the future } \\
\text { Additional operating costs } \\
\text { Additional investment costs } \\
\text { Access to external capital } \\
\text { Access to internal capital } \\
\text { Disruption of operations }\end{array}$ & $\begin{array}{c}\mathrm{I} \\
\mathrm{I} / \mathrm{E} \\
\mathrm{I} \\
\mathrm{E} \\
\mathrm{E} \\
\mathrm{I} \\
\mathrm{I}\end{array}$ \\
\hline Behavioral & $\begin{array}{l}\text { Energy management not a priority of top management } \\
\text { Priority of other investments }\end{array}$ & $\begin{array}{l}\text { I } \\
\text { I }\end{array}$ \\
\hline $\begin{array}{l}\text { Organizational } \\
\text { Competences }\end{array}$ & $\begin{array}{l}\text { Additional workload } \\
\text { Employees lack the right skills }\end{array}$ & $\begin{array}{l}\text { I } \\
\text { I }\end{array}$ \\
\hline
\end{tabular}


Table 2 - Descriptive statistics

\begin{tabular}{|c|c|c|c|c|c|c|}
\hline Variable & $N$ & Median & Mean & Std. Dev. & Min. & Max. \\
\hline \multicolumn{7}{|l|}{ Barriers $^{a}$} \\
\hline Technological measures unknown & 79 & 2 & 2.25 & 1.26 & 1 & 5 \\
\hline $\begin{array}{l}\text { Technically infeasible to reduce } \\
\text { peak load }\end{array}$ & 77 & 3 & 2.87 & 1.54 & 1 & 5 \\
\hline $\begin{array}{l}\text { Technical risk of disruption of the } \\
\text { production process }\end{array}$ & 78 & 4 & 4.04 & 1.20 & 1 & 5 \\
\hline Risk of lower product quality & 78 & 4 & 3.85 & 1.28 & 1 & 5 \\
\hline Data security (company secrets) & 78 & 2 & 2.18 & 1.19 & 1 & 5 \\
\hline Electricity cost savings uncertain & 74 & 3 & 3.18 & 1.44 & 1 & 5 \\
\hline Financial implications not known & 74 & 3 & 2.91 & 1.31 & 1 & 5 \\
\hline Future regulations not known & 74 & 3.5 & 3.53 & 1.44 & 1 & 5 \\
\hline Restrictive regulatory framework & 65 & 3 & 3.48 & 1.17 & 1 & 5 \\
\hline Complex regulatory framework & 69 & 3 & 3.07 & 1.34 & 1 & 5 \\
\hline Electricity cost savings are low & 75 & 3 & 3.19 & 1.37 & 1 & 5 \\
\hline Cost savings too far in the future & 71 & 3 & 2.68 & 1.27 & 1 & 5 \\
\hline Additional operating costs & 76 & 3 & 3.07 & 1.26 & 1 & 5 \\
\hline Additional investment costs & 74 & 3 & 3.30 & 1.39 & 1 & 5 \\
\hline Access to external capital & 63 & 1 & 1.63 & 0.96 & 1 & 5 \\
\hline Access to internal capital & 65 & 2 & 1.92 & 1.06 & 1 & 5 \\
\hline Disruption of operations & 83 & 4 & 3.61 & 1.36 & 1 & 5 \\
\hline $\begin{array}{l}\text { Energy management not a priority } \\
\text { of top management }\end{array}$ & 80 & 1 & 2.04 & 1.34 & 1 & 5 \\
\hline Priority of other investments & 80 & 3 & 3.14 & 1.27 & 1 & 5 \\
\hline Additional workload & 81 & 3 & 2.70 & 1.39 & 1 & 5 \\
\hline Employees lack the right skills & 79 & 2 & 1.92 & 1.06 & 1 & 5 \\
\hline \multicolumn{7}{|l|}{ Dependent variable } \\
\hline Load shift potential (category) & 90 & $3(4-6 \%)$ & 2.88 & 1.61 & $1(<2 \%)$ & $6(>15 \%)$ \\
\hline \multicolumn{7}{|l|}{ Company characteristics } \\
\hline \# Employees in organization & 68 & 1750 & 15,604 & 46,368 & 4 & 300,000 \\
\hline $\begin{array}{l}\text { Organization turnover } \\
\text { (million Euro) }\end{array}$ & 52 & 387.5 & 4,259 & 11,841 & 0.08 & 77,000 \\
\hline Normal load $(\mathrm{kW})$ & 89 & 2,884 & 10,364 & 31,472 & 80 & 280,000 \\
\hline $\begin{array}{l}\text { Electricity expenditures } \\
\text { (thousand Euro) }\end{array}$ & 98 & $1,682.5$ & 5,155 & 13,942 & 16.27 & 125,000 \\
\hline Electricity intensity (Wh/Euro) & 77 & 148.2 & 250 & 406 & 0.01 & 2,255 \\
\hline Batch production dummy & 107 & 0 & 0.17 & 0.38 & 0 & 1 \\
\hline Just-in-Time production dummy & 105 & 0 & 0.20 & 0.40 & 0 & 1 \\
\hline Continuous production dummy & 100 & 1 & 0.61 & 0.49 & 0 & 1 \\
\hline
\end{tabular}


Table 3 - Factor scores (regression-based) for barrier items following principal component analysis and varimax orthogonal rotation

\begin{tabular}{|c|c|c|c|c|c|c|}
\hline \multicolumn{7}{|c|}{ Rotated Component Matrix $^{\mathrm{a}}$} \\
\hline \multirow{2}{*}{ Barrier } & \multicolumn{5}{|c|}{ Component } & \multirow{2}{*}{$\begin{array}{l}\text { Commu- } \\
\text { nalities }\end{array}$} \\
\hline & 1 & 2 & 3 & 4 & 5 & \\
\hline Electricity cost savings are uncertain & 0.800 & -0.08 & -0.010 & 0.235 & -0.104 & 0.712 \\
\hline Low electricity cost savings & 0.740 & 0.022 & 0.107 & 0.136 & 0.198 & 0.618 \\
\hline Future regulations uncertain & 0.735 & 0.058 & -0.009 & -0.203 & 0.296 & 0.673 \\
\hline Energy cost savings too far in the future & 0.695 & 0.102 & 0.304 & 0.152 & -0.124 & 0.624 \\
\hline Regulations too complex & 0.663 & 0.260 & 0.207 & 0.014 & 0.273 & 0.625 \\
\hline Additional operating costs & 0.626 & 0.230 & 0.076 & 0.180 & -0.098 & 0.492 \\
\hline Financial consequences unknown & 0.619 & 0.048 & 0.264 & 0.267 & 0.128 & 0.542 \\
\hline Regulations are too restrictive & 0.596 & 0.302 & -0.364 & 0.005 & 0.164 & 0.606 \\
\hline Required investments too high & 0.546 & 0.078 & 0.466 & 0.340 & -0.436 & 0.828 \\
\hline Technologically impossible to reduce peak load & -0.184 & 0.877 & 0.042 & 0.059 & -0.096 & 0.818 \\
\hline Potential negative impact on product quality & 0.156 & 0.851 & -0.203 & 0.207 & 0.020 & 0.834 \\
\hline Technical risk of production process disruption & 0.253 & 0.846 & -0.053 & 0.125 & 0.122 & 0.813 \\
\hline Interference with personnel planning & 0.232 & 0.772 & 0.226 & -0.016 & 0.198 & 0.741 \\
\hline Lack of (access to) internal capital & 0.233 & 0.061 & 0.801 & -0.201 & 0.117 & 0.754 \\
\hline Lack of access to external capital & -0.004 & -0.165 & 0.756 & 0.209 & -0.021 & 0.643 \\
\hline Technological options unknown & 0.091 & 0.064 & 0.741 & 0.228 & 0.115 & 0.627 \\
\hline Other investments have priority & 0.277 & 0.273 & 0.137 & 0.790 & 0.022 & 0.794 \\
\hline $\begin{array}{l}\text { Energy management not a priority for top } \\
\text { management }\end{array}$ & 0.140 & 0.094 & 0.143 & 0.707 & 0.367 & 0.684 \\
\hline Employees lack skills & 0.078 & 0.057 & 0.264 & 0.318 & 0.774 & 0.780 \\
\hline Data security & 0.378 & 0.384 & -0.083 & 0.136 & 0.471 & 0.537 \\
\hline Additional workload & 0.384 & 0.103 & 0.447 & 0.389 & 0.307 & 0.604 \\
\hline
\end{tabular}


Table 4 - Ordered logit estimates

\begin{tabular}{|c|c|c|}
\hline DV: Reported load shift potential & Coefficient & Odds ratio \\
\hline F1: Financial and Regulatory Risk & $\begin{array}{l}-0.267 \\
(0.302)\end{array}$ & $\begin{array}{c}0.765 \\
(0.231)\end{array}$ \\
\hline F2: Technical Risk & $\begin{array}{c}-0.805^{* *} \\
(0.316)\end{array}$ & $\begin{array}{c}0.447 * * \\
(0.141)\end{array}$ \\
\hline F3: Knowledge of and Access to Options & $\begin{array}{c}0.195 \\
(0.209)\end{array}$ & $\begin{array}{l}1.216 \\
(0.254)\end{array}$ \\
\hline F4: Internal Issue Prioritization & $\begin{array}{c}0.377 \\
(0.288)\end{array}$ & $\begin{array}{c}1.458 \\
(0.420)\end{array}$ \\
\hline F5: Competences & $\begin{array}{c}0.095 \\
(0.203)\end{array}$ & $\begin{array}{c}1.099 \\
(0.223)\end{array}$ \\
\hline $\mathrm{N}$ & \multicolumn{2}{|c|}{46} \\
\hline Log(pseudo likelihood) & \multicolumn{2}{|c|}{-64.40} \\
\hline Wald $\chi^{2}(5)$ & \multicolumn{2}{|c|}{$9.51^{*}$} \\
\hline Pseudo $\mathrm{R}^{2}$ & \multicolumn{2}{|c|}{0.07} \\
\hline
\end{tabular}


Table 5 - Results of two sided t-tests for barriers to load shift and strategic value of electricity

\begin{tabular}{|c|c|c|c|c|c|c|c|c|c|}
\hline \multirow{2}{*}{ Barriers } & \multicolumn{3}{|c|}{ Electricity expenditures } & \multicolumn{3}{|c|}{ Normal electric load } & \multicolumn{3}{|c|}{ Electricity intensity } \\
\hline & samples & $\mathrm{N}$ & $\Delta($ means $)$ & samples & $\mathrm{N}$ & $\Delta($ means $)$ & samples & $\mathrm{N}$ & $\Delta($ means $)$ \\
\hline \multirow{2}{*}{ Lack of access to internal capital } & High & 26 & \multirow{2}{*}{0.183} & High & 26 & \multirow{2}{*}{-0.122} & High & & \multirow{2}{*}{$-0.723^{*}$} \\
\hline & Low & 32 & & Low & 35 & & Low & 27 & \\
\hline \multirow{2}{*}{ Technological options unknown } & & 38 & \multirow{2}{*}{-0.395} & & 36 & \multirow{2}{*}{-0.403} & & 28 & \multirow{2}{*}{$-0.695^{*}$} \\
\hline & & 34 & & & 37 & & & 30 & \\
\hline \multirow{2}{*}{ Additional operating costs } & & 35 & \multirow{2}{*}{$0.605^{*}$} & & 34 & \multirow{2}{*}{0.570} & & 29 & \multirow{2}{*}{-0.107} \\
\hline & & 34 & & & 38 & & & 28 & \\
\hline \multirow{2}{*}{ Electricity cost savings uncertain } & & 32 & \multirow{2}{*}{0.500} & & 31 & \multirow{2}{*}{$0.715^{*}$} & & 27 & \multirow{2}{*}{0.561} \\
\hline & & 35 & & & 39 & & & 28 & \\
\hline \multirow{2}{*}{ Regulations too restrictive } & & 28 & \multirow{2}{*}{$0.599 *$} & & 26 & \multirow{2}{*}{0.331} & & 22 & \multirow{2}{*}{$0.909 * *$} \\
\hline & & 31 & & & 35 & & & 28 & \\
\hline \multirow{2}{*}{ Future regulations uncertain } & & 32 & \multirow{2}{*}{$0.891 * *$} & & 31 & \multirow{2}{*}{0.396} & & 30 & \multirow{2}{*}{0.148} \\
\hline & & 35 & & & 39 & & & 27 & \\
\hline
\end{tabular}

Table 6 - Results of two sided t-tests for barriers to load shift and type of production process

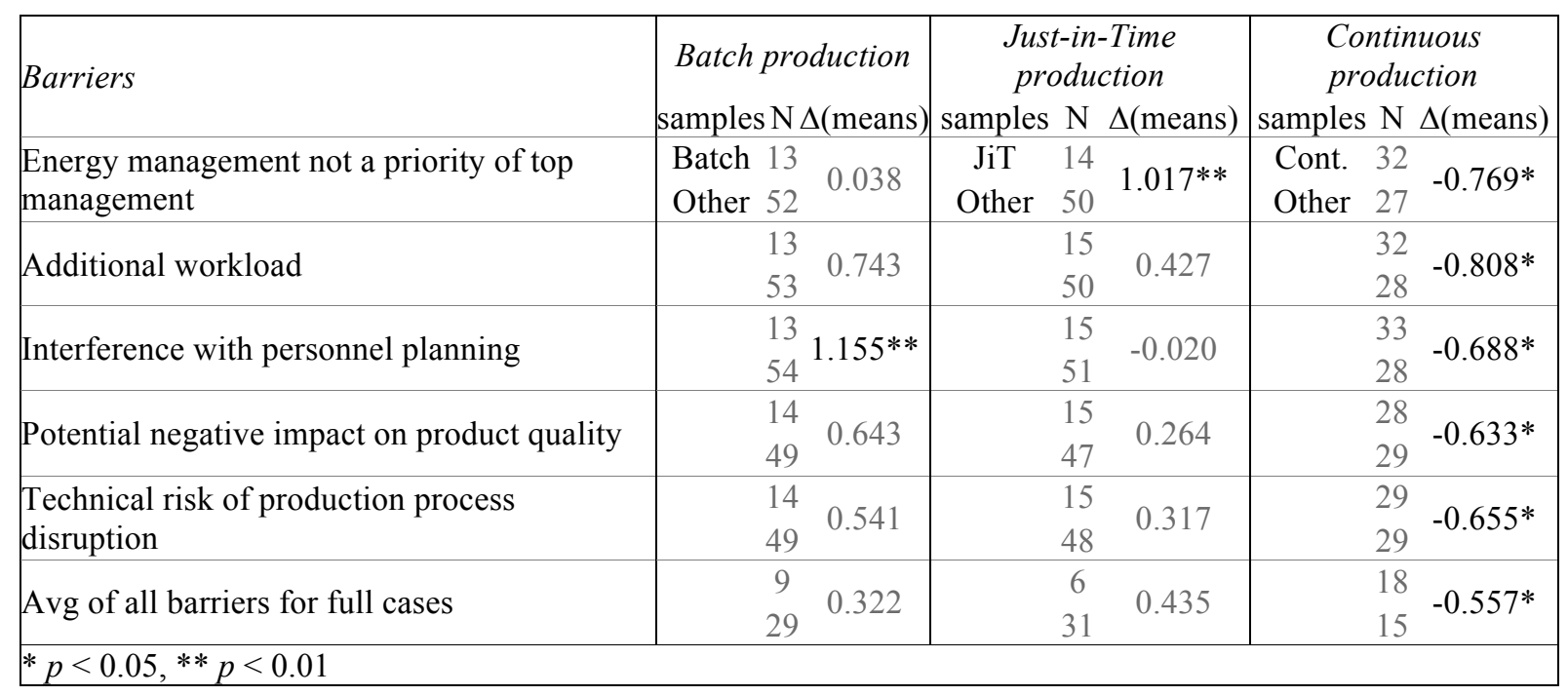

